well they are borne out by experience. If they are confirmed, then we will have taken one step closer to the central black hole that we believe lies at the heart of every quasar. Even if the disk-wind model for line formation perishes, it will do so nobly as it will have rightly forced photoionization modellers to pay far more attention to the dynamical state of their gas clouds than they have been wont to do in the past.

Roger D. Blandford is in the Department of Theoretical Astrophysics, California Institute of Technology, Pasadena, California 91125, USA.

\title{
A twofold tragedy unfolds
}

\section{Peter Hammerstein}

ADAM Smith considered that competition between businessmen tends to promote the well-being of society, but when it is unchecked competition can have quite the opposite effect. It is not just humans that need to keep competition under control, and on page 520 of this issue ${ }^{1}$ Frank proposes a model to explain how genetic evolution can exert such restraining mechanisms.

When too many individuals use renewable resources that are scarce but freely available, the unnecessary degradation of these resources is typically a consequence ${ }^{2}$. For example, communal pastures may be overgrazed as a result of a dairy farmer bringing in extra cattle in order to produce more milk for himself, even though his behaviour reduces the total milk production on the pasture, forcing other farmers to share the cost of his behaviour.

Many human communities have reacted to this 'tragedy of the commons' by introducing institutions that limit access to public resources ${ }^{3}$. For example, an alpine village in Switzerland imposed the socalled 'winter rule' by which no citizen was allowed to send more cows to the public meadows than he could feed during the winter ${ }^{4}$. This rule was enforced by inspection and substantial fines. The citizens had to pay a price for maintaining this policing mechanism which enhanced their overall economic efficiency. A look to biology also turns up examples of policing, and Frank's general selection model ${ }^{1}$ addresses the question of how genetic evolution can generate this costly control and thereby resolve the tragedy of the commons.

What examples do we have of biological policing? Perhaps the most intriguing case of regulated competition is in the intraorganismic process of meiosis, during which two homologous chromosomes are both given a fair chance of entering vehicles (gametes) into the next generation. Furthermore, chromosomes themselves probably evolved from unlinked genes as a means to escape the tragedy of the commons within protocells. Chromosomes keep mutually cooperative genes together by genetic linkage. This reduces a cooperative gene's risk of being exploited by others that replicate particularly fast at the expense of overall cell performance.
Chromosomes are an expensive means of defeating the tragedy of the commons as their replication is slow compared with isolated genes ${ }^{5}$.

At the organismic level, social insects are particularly promising subjects for the study of policing mechanisms. Despite the hierarchy implicit in the terms 'queen' and 'workers', the workers themselves seem to exert most of the control over large colonies $^{6}$, including the active prevention of egg-laying by others.

Rather than dealing with an example in detail, Frank makes an attempt to discuss some general conditions under which policing mechanisms can evolve. In his model he looks at an evolving population in which individuals (or smaller units) interact in groups. Within a group there is a certain degree of genetic relatedness. Individuals can behave very competitively or exert some degree of self-restraint. Their reproductive success relative to other group members depends on their competitiveness. There is also a selection effect at a higher level in that intra-group competition decreases group performance. The second strategic parameter is an individual's contribution to policing. The policing mechanism as such is not made explicit in the model. As the group's total contribution to policing increases, policing progressively reduces the negative effect of intra-group competition.

Frank emphasizes the following conclusion from his analysis. A high degree of relatedness between group members counteracts the evolution of policing. The essential reason is that self-restraint based on the logic of kin selection can achieve for free what expensive policing would bring about. Now, if one looks at sufficiently low degrees of relatedness, this argument breaks down. Contributions will then be made to the policing mechanism provided it is cheap enough. Frank finds it surprising how strongly natural selection favours these contributions in his model. $\mathrm{He}$ also maintains that there will be a double moral standard: pay for policing but strive very competitively for your own success in the group.

If it can evolve so easily, why is policing not found more often in nature, and why are those evolutionary steps fairly exceptional that created higher-level units, such as superorganisms, by suppressing lowerlevel competition ${ }^{7}$ ? To deal with these questions, it pays to have a closer look at Frank's model. In my opinion, one aspect of his mathematical results needs particular attention, although it is not emphasized in his paper. Frank's policing equilibrium only exists if a rather stringent condition is satisfied. This condition requires the individual cost of policing to be kept within a limit that depends on genetic relatedness. This limit, however, converges to zero as we look at ever smaller degrees of relatedness. In other words, policing has to be vanishingly cheap in order to evolve in groups of fairly unrelated individuals. But we would hardly expect an almost cost-free mechanism of policing to exist. This very strongly confines the scope for the evolution of policing in Frank's model.

To put this in a wider context: when we look at examples of the tragedy of the commons, we usually find another, similar tragedy associated with it. The refusal to pay for policing has a substantial positive effect on the individual who does not contribute (strong feedback), but the reduced efficiency of the policing mechanism is shared with the competitors (low feedback). This creates an incentive not to pick up the tab, so the tragedy of the commons is twofold. In biological evolution the second tragedy makes it very difficult to overcome the first.

From Frank's paper we learn that the second tragedy becomes a little less dramatic when there is genetic relatedness. Intuitively, this can be seen if one thinks of the problem in terms of personal fitness. As strategies of relatives are correlated, an individual's payment for policing gets multiplied by the correlated payments of its relatives. Intermediate levels of relatedness therefore facilitate the evolution of policing. This is the major takehome message of Frank's paper. But it does not follow from his study that policing should evolve under many circumstances. The escape route of the tragedy of the commons is too easily blocked by the associated cost tragedy. This will only become transparent if we develop models with explicit mechanisms of policing.

Peter Hammerstein is at the Max Planck Institute for Animal Behaviour Research, D-82319 Seewiesen, Germany.

1. Frank, S. A. Nature 377, 520-522 (1995).

2. Hardin, G. Science 162, 1243-1248 (1968).

3. Ostrom, E. Governing the Commons: The Evolution of Institutions for Collective Action (Cambridge Univ. Press, New York, 1990).

4. Netting, R. M. Human Ecology 4, 135-146 (1976)

5. Maynard Smith, J. \& Szathmáry, E. J. theor. Biol. 164 437-466 (1993).

6. Keller, L. \& Nonacs, P. Anim. Behav. 45, 787-794 (1993).

Maynard Smith, J. \& Szathmáry, E. The Major Transitions in Evolution (Freeman, Oxford, 1995). 